\title{
The Treatment of Autosomal Dominant Polycystic Kidney Disease
}

\author{
E. Wolfgang Kühn, Gerd Walz
}

\section{SUMMARY}

Background: About one in 2000 persons in Europe suffers from autosomal dominant polycystic kidney disease (ADPKD). The treatment of this disease up to the present has been limited to the management of complications.

Method: This review is based on pertinent publications, mostly of the last three years, that were retrieved by a selective search in PubMed.

Results: Kidney volume is probably the most important predictive factor for the loss of renal function. A measurement of kidney size is, therefore, recommended as soon as the diagnosis is made. ADPKD patients under age 30 with a combined kidney volume above $1500 \mathrm{~mL}$ and an estimated glomerular filtration rate (eGFR) below $90 \mathrm{~mL} / \mathrm{min}$ are at high risk of needing kidney-replacement therapy (dialysis or transplantation) within 20 years, even if their renal function is normal. Ultrasonographic follow-up can identify affected persons whose risk for rapid progression is especially high. Currently available evidence reveals that, in patients at risk whose renal function is normal, the maintenance of blood pressure at or below a target value of $110 / 75 \mathrm{mmHg}$ lessens renal enlargement, albuminuria, and left-ventricular hypertrophy. In another study, the treatment of selected patients with tolvaptan, a vasopressin-2 receptor (V2R) blocker, was found to delay cyst enlargement and the related decline in renal function for three years. It is unclear, however, how long the effect of tolvaptan persists, or whether persons whose renal function is already impaired can benefit from it. The main side effects are marked polyuria and, in rare cases, liver toxicity.

Conclusion: In patients with ADPKD, an effort should be made to keep the arterial blood pressure below $120 / 80 \mathrm{mmHg}$. In patients at high risk of progression whose renal function is still intact (eGFR $>60 \mathrm{~mL} / \mathrm{min}$ ), strict blood pressure control $(<110 / 75 \mathrm{~mm} \mathrm{Hg})$ is indicated, and possibly V2R blockade with tolvaptan as well. Tolvaptan is an expensive drug, and patients taking it must be carefully monitored for hepatotoxicity.

\section{Cite this as:}

Kühn EW, Walz G: The treatment of autosomal dominant polycystic kidney disease. Dtsch Arztebl Int 2015; 112: 884-90.

DOI: 10.3238/arztebl.2015.0884
Department of Nephrology and Primary Care, Medical Center-University of Freiburg: Prof. Dr. med. Kühn, Prof. Dr. med. Walz utosomal dominant polycystic kidney disease (ADPKD) is one of the most common human familial diseases $(1,2)$. However, its prevalence in Europe appears to be less than 1 in 2000, and it is therefore classed as a rare disease by the European Medicines Agency (EMA). In additional to renal cysts, hepatic cysts also often develop (in more than $90 \%$ of patients aged over 35 years) (1). Clinical presentation ranges from asymptomatic cases to severe impairment due to enlargement of the kidneys and liver. ADPKD is characterized by increasing kidney size and gradually decreasing renal function. The majority of patients require dialysis by the age of 60 . In the past, therapy consisted of treatment for complications and arterial hypertension, which almost all patients develop. However, it was unclear whether strict blood pressure control slowed disease progression. Studies conducted in recent years indicate that the decrease in renal function is correlated with kidney size and show that the course of the disease can be influenced in patients at high risk of progression. This information sheds new light on treatment for hypertension and has resulted in tolvaptan being authorized specifically for the treatment of ADPKD in Europe.

\section{Methods}

A selective literature search was performed in PubMed, using the keyword "ADPKD." The search focused on interventional and cohort studies conducted in the last three years. The findings of the Kidney Disease: Improving Global Outcomes (KDIGO) Controversies Conference held in February 2014 were also consulted. Older literature was included if it was considered relevant to interpretation of the studies.

\section{Genetics}

ADPKD is caused by mutations in the polycystic kidney disease 1 (PKD1) or 2 (PKD2) genes; the gene products are denoted polycystin-1 and transient receptor potential PKD-like 2 (TRPP2) (3). Polycystin-1 is a large, membrane-bound receptor, and TRPP2 an ion channel. ADPKD is inherited autosomally and is dominant, i.e. it can usually be detected in one parent. However, in up to $30 \%$ of cases family history provides no useful information, as the spontaneous mutation rate is high (approximately 6 to $8 \%$ ) and progression in parents may be subclinical. 


\section{eGFR (mL/min/1.73 $\left.\mathrm{m}^{2}\right)$}

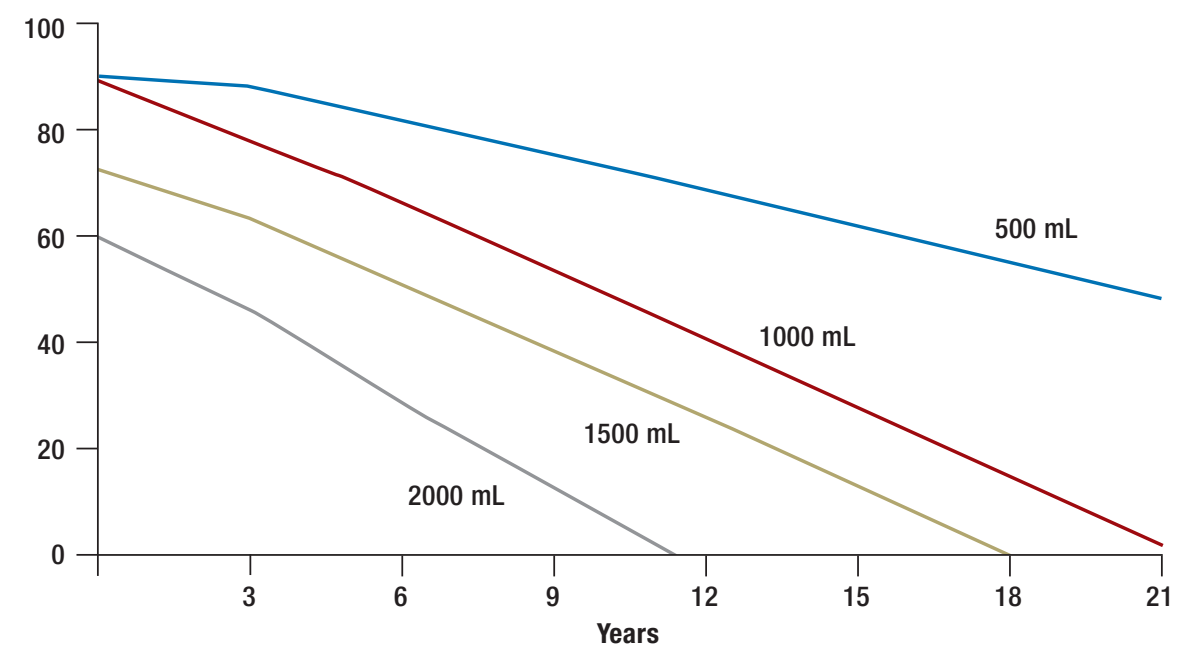

Progression of autosomal dominant polycystic kidney disease and loss of renal function according to age and kidney volume

Calculated progressions of eGFR for a 30-year-old man according to kidney size and function. For example, with a total kidney volume of $2000 \mathrm{~mL}$ and initial GFR of $60 \mathrm{~mL} / \mathrm{min}$, it should be assumed that dialysis will be required (approx. eGFR $<10 \mathrm{~mL}$ / min) within approximately 10 years. Calculation is based on cohort data (8) and has not been validated for clinical practice. More accurate risk estimates may be possible in the future, based on improved algorithms. GFR: Glomerular filtration rate; eGFR: Estimated glomerular filtration rate

\section{Factors affecting progression}

ADPKD is a slow-progressing disease in which the kidneys continually increase in size. The US Consortium for Radiologic Imaging Studies in Polycystic Kidney Disease (CRISP) has shown that kidney enlargement is the first manifestation of the disease. It is not uncommon for total kidney volume (TKV) to reach a volume of more than one liter (normal size is less than $400 \mathrm{~mL}$ ) before there is any loss of function $(4,5)$. PKD2 mutations cause significantly slower cyst growth: renal failure occurs a mean of almost 20 years later than in PKD1 mutations (at age 54.3 versus 74.0 years) (1). Hypomorphic PKD1 mutations, which ensure partial residual function, progress more slowly than mutations that greatly shorten the protein (6). Important prognostic factors on presentation are age, sex, renal function (assessed using the estimated glomerular filtration rate, or eGFR), and onset of arterial hypertension. However, these are probably accounted for in TKV (Figure 1). TKV, often stated in relation to body size $(\mathrm{mL} / \mathrm{m})$, can best be ascertained using standardized magnetic resonance imaging (MRI) protocols and stereological evaluation, but these are only available in specialized centers. Ultrasound measurement of kidney length seems to be just as useful as TKV. In patients with eGFR above $70 \mathrm{~mL} / \mathrm{min}$, TKV determined by ultrasound of more than $650 \mathrm{~mL} / \mathrm{m}$ or kidney length above $16.5 \mathrm{~cm}$ was a predictor of a decrease in eGFR to less than $60 \mathrm{~mL} / \mathrm{min}$ over the following eight years, with a sensitivity of $70 \%$ and specificity of $71 \%$ (7). These parameters are more suitable than creatinine or albuminuria testing. Attempts to extract algorithms from published studies in order to predict individual progression are based on limited data, and their applicability is therefore limited (8). Essentially, however, individual risk assessment will be relevant to treatment decisions in the future. Data is therefore currently being collected in a Europe-wide study on spontaneous disease progression (9). Other risk factors such as albuminuria, left ventricular hypertrophy, smoking, and macrohematuria must also be taken into account when predicting individual progression.

\section{Pathophysiology}

Around 15 years ago, ciliary disorders were identified as a cause of cystic kidney diseases (10). Cilia are hairlike structures located on almost all cells of the body. Polycystin-1 and TRPP2 are located in the cilia, so ADPKD is also called ciliopathy. It is unclear why cilia are necessary during kidney development and how they inhibit renal cysts. In a murine model, cilia seem to be responsible for well-ordered cell division and cell migration along the axis of the nephron $(11,12)$ (Figure 2). Indirect evidence suggests that in ADPKD the mammalian target of the rapamycin complex 1 (mTORC1) signal cascade is more active and that cyclic adenosine monophosphate (cAMP) accumulates $(13,14)$. More than 25 years ago, increased cAMP production was already associated with increased ion and fluid secretion in the lumen of the cyst, and therefore with cyst growth (15). This change is the basis of tolvaptan therapy: the vasopressin 2 receptor blocker (V2RB) inhibits antidiuretic hormone-dependent production of cAMP and therefore hinders cyst growth (Figure 3).

\section{Interventional studies}

Inhibition of mTORC1 activity (16-19) and of cAMP accumulation has been investigated in multiple clinical studies (Table). In one randomized, placebo-controlled trial, although the mTORC1 inhibitor everolimus slowed the increase in kidney volume (TKV) it did not 
Defective cell division and migration as causes of cyst formation Targeted cell division along the axis of the nephron and the continuous formation and dissolution of cell rosettes (five to seven cells that meet at one point) cause the nephron to become elongated. Disruptions to this process lead to renal cysts. The precise role of cilia currently remains unclear.

\section{FIGURE 2}
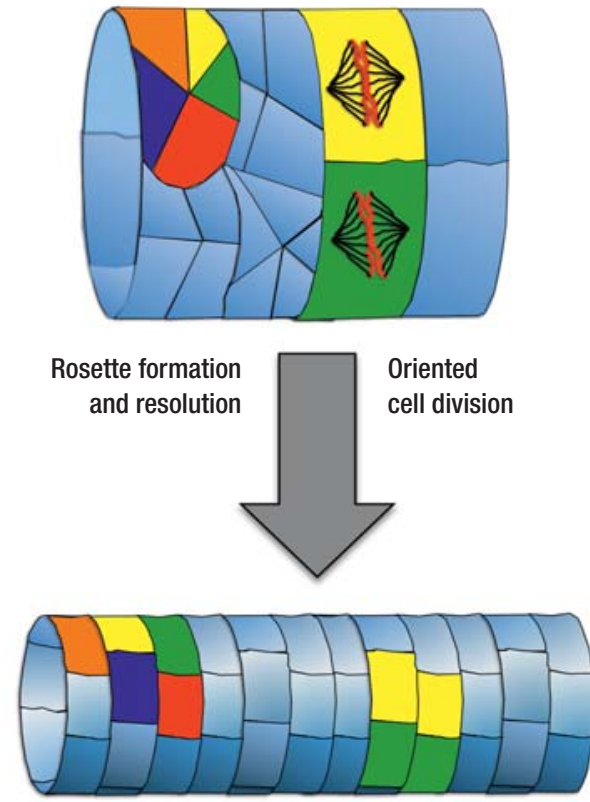

Elongation of nephron
(eGFR 25 to $65 \mathrm{~mL} / \mathrm{min}$ ). In Germany, tolvaptan therapy costs approximately $€ 30000$ per year, which is comparable to the annual cost for renal replacement therapy in Europe (27).

A further possibility for inhibiting cAMP production is the stimulation of $\mathrm{G} \alpha_{\mathrm{i}}$ by somatostatin analogs. In the ALADIN study, the increase in TKV in 38 ADPKD patients treated with octreotide long-acting repeatable (LAR) after 12 months was lower than in the control group ( $46 \mathrm{~mL}$ versus $143 \mathrm{~mL}$ ), but after three years the effect was no longer significantly different, probably as a result of unequal distribution of kidney size and renal function between the groups (28). Of the 38 patients, four suffered cholelithiasis or acute cholecystitis, so this approach must be tested in further studies. In adolescent ADPKD patients with early-stage ADPKD (mean age: 16 years, creatinine clearance: $135 \mathrm{~mL} /$ min), pravastatin delayed kidney enlargement by $2.7 \%$ per year in a single-center study (29) (Table). It is therefore of interest to conduct multicenter studies of statins.

\section{Arterial hypertension}

The HALT-PKD study investigated whether ADPKD progression can be delayed by blockade of the renin angiotensin aldosterone system (RAAS) using a combination of an angiotensin-converting enzyme (ACE) inhibitor and an angiotensin II receptor subtype 1 (AT1) blocker, together with maintaining particularly low blood pressure, $110 / 75 \mathrm{mmHg}$ or less, in patients with eGFR above $60 \mathrm{~mL} / \mathrm{min}$. HALT-PKD was a multicenter US trial conducted in more than 1000 ADPKD patients for 5.5 years $(30,31)$. The group of patients with low target blood pressure ( $95 / 60$ to $110 / 75 \mathrm{mmHg}$ ) showed a delayed increase in TKV and a decrease in left ventricular hypertrophy and proteinuria, but renal function did not improve according to the preestablished criteria. However, these criteria were different from those used in the TEMPO 3/4 study (24), as there was no repeat measurement of renal function when drug treatment was halted at the end of the study (30). This is relevant, as the low blood pressure in the intervention group of HALT-PKD led to a decrease in GFR caused by hemodynamic factors, as seen with tolvaptan. The decrease in GFR following the titration phase in the group with low blood pressure was slower than that in the control group, and the difference was almost significant $(p=0.05)$. The role played by genotype remains unclear, as the percentage of patients with a PKD2 mutation was higher in the group with low blood pressure than in the control group $(20 \%$ versus $13 \%$ ). Genotype distribution in the TEMPO $3 / 4$ study is unknown. This study highlights the fact that a blood pressure of $110 / 75 \mathrm{mmHg}$ or lower is tolerated with no significant cardiovascular comorbidities by young ADPKD patients (mean age: 37 years) (30). Double RAAS blockade with target blood pressure 120/80 mmHg or less produced no benefit, but neither did it lead to an increase in complications among older ADPKD patients (mean age: 49 years) with a GFR of $30 \mathrm{~mL} / \mathrm{min}$ or more (31). 


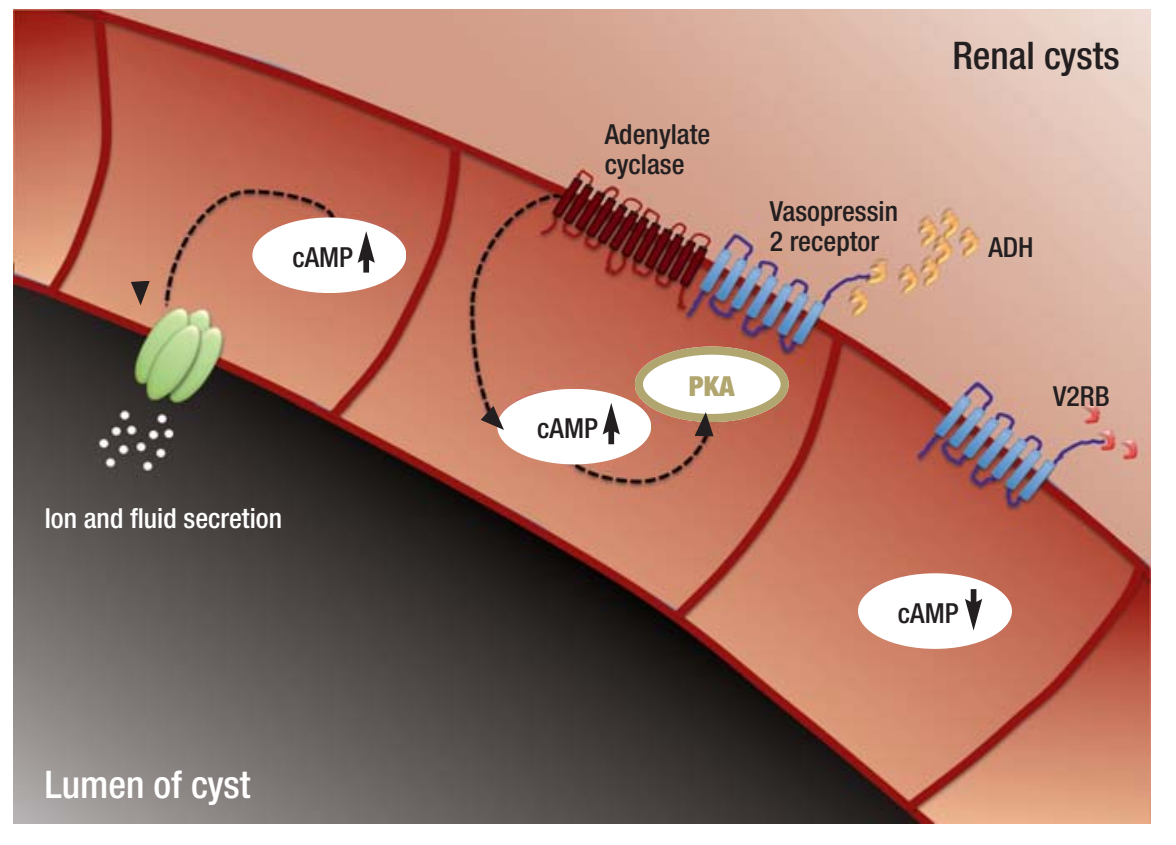

Postulated effects of vasopressin 2 receptor blockade on renal cysts Cyst cells display increased cyclic adenosine monophosphate (CAMP) levels, which can contribute to cyst growth by stimulating ion and fluid secretion, and to cell proliferation by activating protein kinase $\mathrm{A}$ (PKA). Antidiuretic hormone (ADH) promotes cAMP production by stimulating vasopressin 2 receptors and activating membrane-bound adenylate cyclases. Vasopressin 2 receptor blockers (V2RBs) can block ADH-dependent cAMP production.

\section{Management of ADPKD}

Until a few months ago, the supportive treatment measures recommended at the February 2014 KDIGO Controversies Conference, particularly blood pressure control, were the focal point of treatment for ADPKD (6). Study findings from the last three years provide grounds to make the management of ADPKD for patients more specific (Figure 4).

\section{Diagnosis and genetic counselling}

Because until now early diagnosis was primarily associated with disadvantages, screening in children was limited to measurement of blood pressure, in order to provide prompt identification of the most important factor in progression that could be influenced (6). The availability of specific therapies means it is likely that there will be a paradigm shift, as high-risk patients can be identified in childhood and adolescence (32) and may particularly benefit from early treatment (29). Ultrasound can be used to diagnose ADPKD in young patients aged between 15 and 29 years, with more than $96 \%$ accuracy; it is not possible to rule out the disease, however (6). Currently still of minor significance, genetic diagnosis will become more important if better

\section{TABLE}

Changes in kidney volume and renal function in five clinical studies involving 100 patients or more

\begin{tabular}{|c|c|c|c|c|c|c|c|}
\hline Study & $\begin{array}{l}\text { No. of treated } \\
\text { patients }\end{array}$ & $\begin{array}{c}\text { Age } \\
\text { (years) }\end{array}$ & $\begin{array}{l}\text { Baseline TKV } \\
(\mathrm{mL})\end{array}$ & $\begin{array}{l}\text { Baseline eGFR } \\
\left(\mathrm{mL} / \mathrm{min} / 1.73 \mathrm{~m}^{2}\right)\end{array}$ & $\begin{array}{c}\Delta \text { TKV vs. placebo } \\
\text { (\% per year) }\end{array}$ & $\begin{array}{c}\Delta \text { eGFR vs. placebo } \\
\text { (mL/min/1.73 } \mathrm{m}^{2} \text { per year) }\end{array}$ & $\begin{array}{l}\text { Relative } \\
\text { stage }^{* 2}\end{array}$ \\
\hline Pravastatin (29) & 56 & 16 & 571 & $135^{* 1}$ & $-2.7\left(^{*}\right)$ & 0.0 & 1 \\
\hline Sirolimus (17) & 50 & 31 & 907 & 92 & 0.2 & 2.5 & 3 \\
\hline HALT-PKD (30) & 274 & 37 & 1185 & 91 & $-1.0\left(^{*}\right)$ & 0.4 & 5 \\
\hline TEMPO 3/4 (24) & 961 & 39 & 1705 & 81 & $-2.7\left(^{*}\right)$ & $1.0\left(^{*}\right)$ & 8 \\
\hline Everolimus (18) & 213 & 45 & 2028 & 53 & $-2.2\left(^{*}\right)$ & -2.0 & 17 \\
\hline
\end{tabular}

Significantly lower TKV $\left(^{*}\right)$ led to a significant delay in loss of renal function $\left(^{*}\right)$ in the TEMPO $3 / 4$ study only. The difference between the intervention and placebo groups was $1.0 \mathrm{~mL} /$ $\mathrm{min} / 1.73 \mathrm{~m}^{2}$ per year. The relative stage was ascertained by multiplying kidney volume (TKV in $\mathrm{dL}$ ) by age and dividing by renal function; it illustrates the various stages of ADPKD at which the studies were conducted ( 1 = early stage, 17 = advanced stage). This difference should be taken into account when comparing different ADPKD studies.

ADPKD: Autosomal dominant polycystic kidney disease; TKV: Total kidney volume; eGFR: Estimated glomerular filtration rate;

HALT-PKD: Halt Progression of Polycystic Kidney Disease; TEMPO 3/4: Tolvaptan Efficacy and Safety in Management of ADPKD and Its Outcomes 3/4

$\left({ }^{*}\right)$ : Denotes significance

${ }^{\star 1}$ Creatinine clearance

${ }^{* 2}$ Relative stage $=$ TKV $(\mathrm{dL}) \times$ age $($ years $) /$ eGFR $\left(\mathrm{mL} / \mathrm{min} / 1.73 \mathrm{~m}^{2}\right)$ 


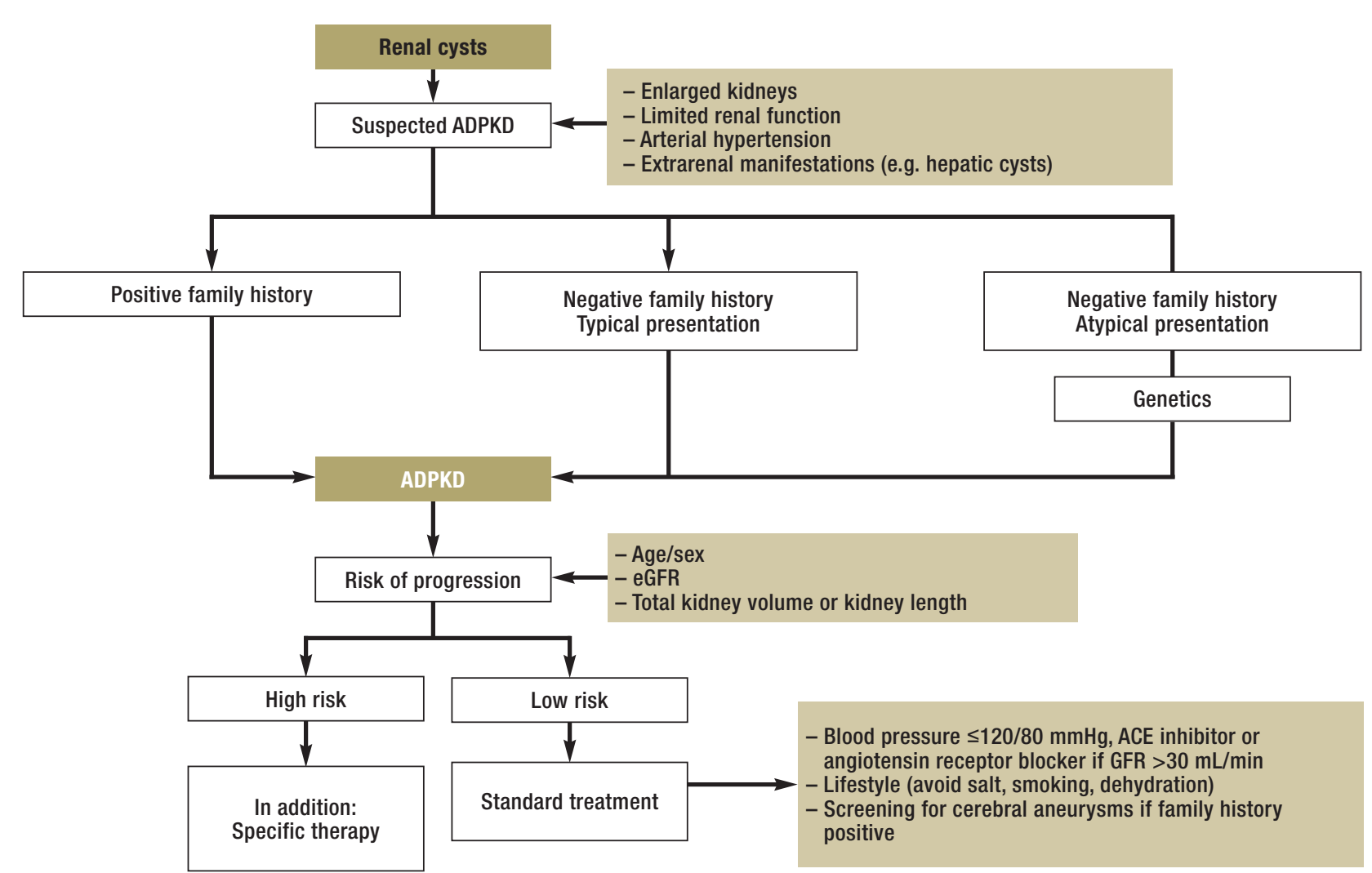

Flow diagram to confirm and treat ADPKD

Bilateral renal cysts with enlarged kidneys and limited renal function in the context of extrarenal manifestations such as hepatic cysts and arterial hypertension lead to a diagnosis of ADPKD if family history is positive. If family history is negative (approx. $30 \%$ of cases), and if screening of relatives is negative (approx. $10 \%$ ), diagnosis is largely certain if manifestation is typical, and it should be assumed that this is an initial manifestation. If manifestation is atypical, further genetic diagnostic testing is recommended. The best method of estimating the risk of progression is currently kidney volume in combination with age, sex, and renal function (eGFR). ACE: Angiotensin-converting enzyme; ADPKD: Autosomal dominant polycystic kidney disease; GFR: Glomerular filtration rate; eGFR: Estimated glomerular filtration rate

correlations between genotype and phenotype can be identified in the future, and if there are consequences for treatment before ADPKD becomes manifest. Costs have fallen significantly as a result of high throughput, and unambiguous diagnosis is possible in $90 \%$ of cases (33). The question of genetic counseling for those who wish to undergo preimplantation diagnostics remains difficult. Technically possible, but associated with complications and errors, in Germany this decision is made by ethics committees established specially for this purpose and is currently reserved for serious hereditary diseases.

\section{Prognosis}

For many patients, the prospect of terminal renal insufficiency and the beginning of renal replacement therapy is crucial. Many personal decisions such as family and career planning depend on the prognosis for progression. Although stratification of risk based on age, renal function, and TKV has not yet been clinically validated, on average it can be assumed that the risk of progression is correlated with kidney size. Accordingly, at the KDIGO Conference in 2014 a baseline examination to determine kidney size was recommended (6). MRI with a standardized protocol in specialized centers can be used for this. A modified ellipsoid formula based on the parameters height, width, and depth can be used to estimate kidney size by ultrasound. However, such formulae cannot be used for asymmetrical kidneys and overestimate kidney size by approximately $25 \%$. A recent publication shows that kidney length above $16.5 \mathrm{~cm}$ is a predictor of a decrease in renal function (7).

\section{Blood pressure control}

Unlike for chronic renal failure, for which a relatively high target blood pressure of $140 / 90 \mathrm{mmHg}$ or less is currently recommended (34) - not uncontroversially-the HALT-PKD study supports strict blood pressure control with significantly lower target levels $(30,31)$. On the basis of studies conducted to date, in young patients at high risk of progression (enlarged 
kidneys, family history regarding age at time of kidney failure, proteinuria, macrohematuria) and eGFR above $60 \mathrm{~mL} / \mathrm{min}$, target blood pressure should be less than $110 / 70 \mathrm{mmHg}$. In patients with eGFR 30 to $60 \mathrm{~mL} / \mathrm{min}$, target blood pressure is less than $120 / 80 \mathrm{mmHg}$. It is important that blood pressure measurement is validated using self-readings or 24-hour blood pressure profiles. In patients with stage 4 renal insufficiency (eGFR below $30 \mathrm{~mL} / \mathrm{min}$ ) or cardiovascular disease, this type of strict blood pressure control cannot be used, as there may be hemodynamically negative effects on renal function.

\section{Specific therapies}

Tolvaptan has been authorized in Germany and can be prescribed for patients at high risk of progression. It is subject to a risk minimization program due to the danger of liver damage. Physicians who prescribe tolvaptan must be registered and must check patients' liver enzyme levels every month for $1 \frac{1}{2}$ years. In the TEMPO $3 / 4$ study $38 \%$ of patients suffered polyuria (17\% in the placebo group), and $29 \%$ suffered nocturia (13\% in the placebo group) (24). With urine volume above 7 L per day (35), polyuria and nocturia significantly influence everyday life which is certainly not acceptable for all patients and which led to a study dropout rate of $23 \%$. It is therefore particularly important to identify the patients who will benefit the most. Patients aged 30 years or younger with enlarged kidneys (TKV $1500 \mathrm{~mL}$ or more) and eGFR below $90 \mathrm{~mL} / \mathrm{min}$ are at high risk of progression. These patients are very likely to require renal replacement therapy within 20 years. In order to decide on a specific treatment and monitor patients sufficiently, a specific treatment in reference centers is useful. Statin therapy should be discussed in individual cases; statins may slow kidney growth in adolescents. No general recommendation can currently be given on this based on the strength of studies conducted to date.

\section{General measures}

Increased fluid intake and restricted coffee consumption are recommended, but there is no solid basis for these recommendations $(36,37)$. Smoking has been shown to be damaging. Moderately increased fluid intake, 2 to $3 \mathrm{~L}$, appears to be beneficial. A diet rich in salt and protein should be avoided.

\section{The outlook for ADPKD treatment}

The US National Institutes of Health (NIH) website for clinical trials (www.clinicaltrials.gov) currently lists more than 70 studies concerning ADPKD. In addition to observational studies, triptolides, spironolactone, somatostatin analogs, and niacinamide are being investigated in pilot studies. In animal models, multiple signal cascades have been identified that inhibit the growth of kidney cysts. However, paradoxically, accelerated cyst growth is also occasionally observed. These findings indicate a phenomenon observed in oncology: when a signal cascade is inhibited, bypass signal cascades are activated, and these promote tumor or cyst growth more strongly than the original growth signals. It is therefore probable that effective ADPKD therapy, like tumor therapy, must be administered as sequential or combination therapy. A recent Cochrane review that included 30 studies with a total of 2039 ADPKD patients therefore, unsurprisingly, comes to the conclusion that current therapies are only marginally effective, and that further randomized trials are needed in order to improve individual prognosis for patients (38).

\section{Conflict of interest statement \\ Prof. Kühn has received lecture fees and reimbursement of travel expenses from Fresenius. \\ Prof. Walz has received lecture fees and fees for advisory board meetings from Otsuka and Alexion.}

Manuscript received on 13 April 2015, revised version accepted on 9 September 2015.

Translated from the original German by Caroline Shimakawa-Devitt, M.A.

\section{REFERENCES}

1. Torres VE, Harris PC, Pirson Y: Autosomal dominant polycystic kidney disease. Lancet 2007; 369: 1287-301.

2. Ong AC, Devuyst O, Knebelmann B, Walz G: Autosomal dominant polycystic kidney disease: the changing face of clinical management. Lancet 2015; 385:1993-2002.

3. Kuehn EW, Walz G: [Autosomal dominant polycystic kidney disease]. Dtsch Arztebl 2007; 104: A3022-8.

4. Grantham JJ, Torres VE, Chapman AB, et al.: Volume progression in polycystic kidney disease. N Engl J Med 2006; 354: 2122-30.

5. Chapman AB, Bost JE, Torres VE, et al.: Kidney volume and functional outcomes in autosomal dominant polycystic kidney disease. Clin J Am Soc Nephrol 2012; 7: 479-86.

6. Chapman AB, Devuyst O, Eckardt KU, et al.: Autosomal-dominant polycystic kidney disease (ADPKD): executive summary from a Kidney

\section{KEY MESSAGES}

- Autosomal dominant polycystic kidney disease (ADPKD) leads to arterial hypertension and extrarenal manifestations such as hepatic cysts. More than $50 \%$ of patients suffer from renal failure during the course of the disease.

- The risk of renal failure is correlated with total kidney volume.

- ADPKD patients aged under 30 years with kidney volume above $1500 \mathrm{~mL}$ are highly likely to require renal replacement therapy within approximately 20 years, even if their current kidney function is close to normal.

- In patients at high risk of progression, treatment with a vasopressin 2 receptor antagonist can be considered in addition to treatment of complications and control of blood pressure at low normal levels.

- The use of a specific therapy must be considered in the context of side effects and personal lifestyle. 
Disease: Improving Global Outcomes (KDIGO) Controversies Conference. Kidney Int 2015; 88: 17-27.

7. Bhutani H, Smith V, Rahbari-Oskoui F, et al.: A comparison of ultrasound and magnetic resonance imaging shows that kidney length predicts chronic kidney disease in autosomal dominant polycystic kidney disease. Kidney Int 2015; 88: 146-51.

8. Irazabal MV, Rangel LJ, Bergstralh EJ, et al.: Imaging classification of autosomal dominant polycystic kidney disease: a simple model for selecting patients for clinical trials. J Am Soc Nephrol 2015; 26: 160-72.

9. Petzold K, Gansevoort RT, Ong AC, et al.: Building a network of ADPKD reference centres across Europe: the EuroCYST initiative. Nephrol Dial Transplant 2014; 29: 26-32.

10. Hildebrandt F, Benzing T, Katsanis N: Ciliopathies. N Engl J Med 2011; 364: 1533-43.

11. Fischer $E$, Legue E, Doyen A, et al.: Defective planar cell polarity in polycystic kidney disease. Nat Genet 2006; 38: 21-3.

12. Lienkamp SS, Liu K, Karner CM, et al.: Vertebrate kidney tubules elongate using a planar cell polarity-dependent, rosette-based mechanism of convergent extension. Nat Genet 2012; 44: 1382-7.

13. Ibraghimov-Beskrovnaya 0 , Natoli TA: mTOR signaling in polycystic kidney disease. Trends Mol Med 2011; 17: 625-33.

14. Harris PC, Torres VE: Genetic mechanisms and signaling pathways in autosomal dominant polycystic kidney disease. J Clin Invest 2014; 124: 2315-24.

15. Mangoo-Karim R, Uchic M, Lechene C, Grantham JJ: Renal epithelial cyst formation and enlargement in vitro: dependence on cAMP. Proc Natl Acad Sci USA 1989; 86: 6007-11.

16. Perico N, Antiga L, Caroli A, et al.: Sirolimus therapy to halt the progression of ADPKD. J Am Soc Nephrol 2010; 21: 1031-40.

17. Serra AL, Poster D, Kistler AD, et al.: Sirolimus and kidney growth in autosomal dominant polycystic kidney disease. N Engl J Med 2010; 363 $820-9$

18. Walz G, Budde K, Mannaa M, et al.: Everolimus in patients with autosomal dominant polycystic kidney disease. N Engl J Med 2010; 363: 830-40.

19. Braun WE, Schold JD, Stephany BR, Spirko RA, Herts BR: Low-dose rapamycin (sirolimus) effects in autosomal dominant polycystic kidney disease: an open-label randomized controlled pilot study. Clin J Am Soc Nephrol 2014; 9: 881-8.

20. Grahammer F, Haenisch N, Steinhardt F, et al:: mTORC1 maintains renal tubular homeostasis and is essential in response to ischemic stress. Proc Natl Acad Sci U S A 2014; 111: E2817-26.

21. Wang X, Gattone V 2nd, Harris PC, Torres VE: Effectiveness of vasopressin V2 receptor antagonists OPC-31260 and OPC-41061 on polycystic kidney disease development in the PCK rat. J Am Soc Nephrol 2005; 16 846-51.

22. Torres VE, Wang X, Qian Q, Somlo S, Harris PC, Gattone VH 2nd: Effective treatment of an orthologous model of autosomal dominant polycystic kidney disease. Nat Med 2004; 10: 363-4

23. Gattone VH 2nd, Wang X, Harris PC, Torres VE: Inhibition of renal cystic disease development and progression by a vasopressin V2 receptor antagonist. Nat Med 2003; 9: 1323-6.

24. Torres VE, Chapman AB, Devuyst 0 , et al.: Tolvaptan in patients with autosomal dominant polycystic kidney disease. N Engl J Med 2012; 367 2407-18.
25. FDA: Briefing Document. Cardiovascular and Renal Drug Advisory Committee Meeting 2013. www.fda.gov/downloads/AdvisoryCom mittees/CommitteesMeetingMaterials/Drugs/CardiovascularandRenalDrugsAdvisoryCommittee/UCM363343.pdf (last accessed on 16 October 2015)

26. Erickson KF, Chertow GM, Goldhaber-Fiebert JD: Cost-effectiveness of tolvaptan in autosomal dominant polycystic kidney disease. Ann Intern Med 2013; 159: 382-9.

27. Spithoven EM, Kramer A, Meijer E, et al.: Renal replacement therapy for autosomal dominant polycystic kidney disease (ADPKD) in Europe: prevalence and survival-an analysis of data from the ERA-EDTA Registry. Nephrol Dial Transplant 2014; 29: 15-25

28. Caroli A, Perico N, Perna A, et al.: Effect of longacting somatostatin analogue on kidney and cyst growth in autosomal dominant polycystic kidney disease (ALADIN): a randomised, placebo-controlled, multicentre trial. Lancet 2013; 382: 1485-95.

29. Cadnapaphornchai MA, George DM, McFann K, et al.: Effect of pravastatin on total kidney volume, left ventricular mass index, and microalbuminuria in pediatric autosomal dominant polycystic kidney disease. Clin J Am Soc Nephrol 2014; 9: 889-96.

30. Schrier RW, Abebe KZ, Perrone RD, et al.: Blood pressure in early autosomal dominant polycystic kidney disease. N Engl J Med 2014; 371: 2255-66.

31. Torres VE, Abebe KZ, Chapman AB, et al.: Angiotensin blockade in late autosomal dominant polycystic kidney disease. N Engl J Med 2014; 371 $2267-76$.

32. Helal I, Reed B, McFann K, et al.: Glomerular hyperfiltration and renal progression in children with autosomal dominant polycystic kidney disease. Clin J Am Soc Nephrol 2011; 6: 2439-43.

33. Rossetti S, Consugar MB, Chapman AB, et al.: Comprehensive molecular diagnostics in autosomal dominant polycystic kidney disease. J Am Soc Nephrol 2007; 18: 2143-60

34. Wheeler DC, Becker GJ: Summary of KDIGO guideline. What do we really know about management of blood pressure in patients with chronic kidney disease? Kidney Int 2013; 83: 377-83.

35. Shoaf SE, Wang Z, Bricmont P, Mallikaarjun S: Pharmacokinetics, pharmacodynamics, and safety of tolvaptan, a nonpeptide AVP antagonist, during ascending single-dose studies in healthy subjects. J Clin Pharmacol 2007; 47: 1498-507.

36. Sarnak MJ, Greene T, Wang X, et al.: The effect of a lower target blood pressure on the progression of kidney disease: long-term follow-up of the modification of diet in renal disease study. Ann Intern Med 2005; 142: 342-51.

37. Torres VE, Grantham JJ, Chapman AB, et al.: Potentially modifiable factors affecting the progression of autosomal dominant polycystic kidney disease. Clin J Am Soc Nephrol 2011; 6: 640-7.

38. Bolignano D, Palmer SC, Ruospo M, Zoccali C, Craig JC, Strippoli GF: Interventions for preventing the progression of autosomal dominant polycystic kidney disease. Cochrane Database Syst Rev 2015; 7 CD010294.

\section{Corresponding author:}

Prof. Dr. med. Gerd Walz

Department Innere Medizin IV, Universitätsklinikum Freiburg

Hugstetter Str. 55

79106 Freiburg, Germany

gerd.walz@uniklinik-freiburg.de 